\title{
OUTCOME OF TOBACCO SMOKING HABIT ON LIPID PEROXIDATION AND ANTIOXIDANT PARAMETERS IN ANEMIC INDIVIDUALS
}

\author{
Nirjala Laxmi Madhikarmi ${ }^{1 *}$, Madhav Gautam ${ }^{2}$
}

\begin{abstract}
Affiliation
1. Associate Professor, Department of Biochemistry, Kantipur Dental College Teaching Hospital \& Research Center, Nepal

2. Professor, Department of Biochemistry, Kantipur Dental College Teaching Hospital \& Research Center, Nepal
\end{abstract}

\section{ARTICLE INFO}

Received : 02 March, 2021

Accepted : 22 May, 2021

Published : 04 November 2021

(c) Authors retain copyright and grant the journal right of first publication with the work simultaneously licensed under Creative Commons Attribution License CC - BY 4.0 that allows others to share the work with an acknowledgment of the work's authorship and initial publication in this journal.

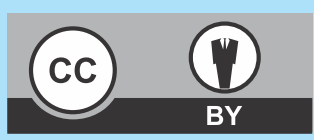

ORA 255

DOI: https://doi.org/10.3126/bjhs.v6i2.40329

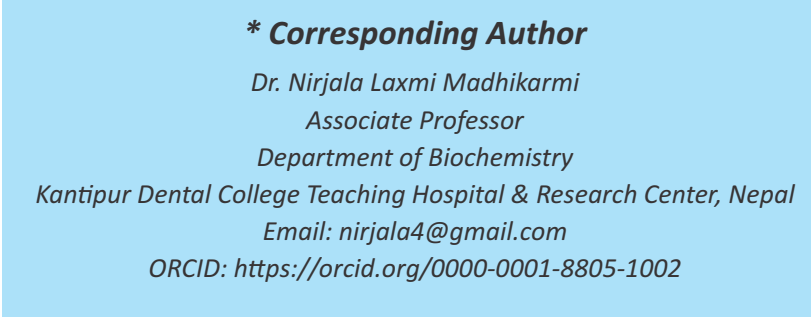

\section{Citation}

Nirjala Laxmi Madhikarmi, Madhav Gautam. Outcome of Tobacco Smoking Habit on Lipid Peroxidation and Antioxidant parameters in Anemic Individuals. BJHS 2021;6(2)15. 1481-1485.

\section{ABSTRACT \\ Introduction}

Globally tobacco smoking is considered as a foremost public health problem. Erythrocytes membrane lipids are rich in polyunsaturated fatty acids and the oxidative effects of oxygen on its membrane are greater than other tissues and the condition is heightened by tobacco smoke.Free radicals present in the tobacco increases peroxidation products in blood and vascular tissues are chiefly responsible for harmful effects.

\section{Objective}

The present study was designed to investigate the impact of stress induced by tobacco smoke on lipid peroxidation and antioxidant parameters in patients with anemia.

\section{Methodology}

A hospital-based case-control study was carried out in Kantipur Dental College Teaching Hospital, included 150 tobacco smoking anemic and 150 healthy volunteers. The stress parameter was assessed by the determination of malondialdehyde, lipid hydroperoxide and nitric oxide. The non-enzymatic antioxidants such as vitamins $A, C$ and $E$ and total antioxidant activity and enzymatic antioxidants were catalase, superoxide dismutase and glutathione peroxidase were also determined.

\section{Result}

Hemoglobin level in anemic smokers showed raised level as compared to healthyindividualsbutthere was diminished antioxidants status and elevated free radical parameters in anemicsmokersdespite their raised hemoglobinstatus.We found statistically increased malondialdehyde, lipid hydroperoxide and nitric oxide levels and decreased enzymatic and non-enzymatic antioxidant status, thus increasing the oxidative stress.

\section{Conclusion}

The present study showed high concentration of hemoglobin, low status of non-enzymatic antioxidants and high levels of oxidants as compared to controls reflecting the destructive and oxidative effects of tobacco smoke.

\section{KEYWORDS}

Anemia; antioxidant; lipid peroxidation; smoking, tobacco. 


\section{INTRODUCTION}

Globally 2 billion people are estimated to be suffering from anemia and smoking is a public health problem throughout the globe and is known to affect antioxidants level. ${ }^{1}$ Globally, one in three adults, or 1.2 billion people smoke and about $82 \%$ reside in low- and middle-income countries. ${ }^{2,3}$

Free radicals are continuously produced by the body's normal use of oxygen. Cells use oxygen to generate energy and free radicals are produced by the mitochondria. A normal cell balances between formation and removal of free radicals. However, balance is shifted towards more formation of free radicals as cigarette smoke produces number of hazardous chemicals compounds including free radicals. ${ }^{4,5}$ Approximately, cigarettes produce 7000 chemicals, each puff contains $10^{15}$ low molecular weight free radicals which initiate and propagate lipid. ${ }^{3,6}$

Studies has been carried out in smoking, anemia, antioxidants, free radicals in separate form but lack of combined research on anemic smokers against antioxidants- free radicals made us chose this topic. In smoking and anemia context we designed to investigate impact of stress induced by cigarette on lipid peroxidation, enzymatic and non-enzymatic antioxidants. $^{1,5-8}$

\section{METHODOLOGY}

A hospital based case-control study carried out in Kantipur Dental College Teaching Hospital \& Research Center, Basundhara, Kathmandu from March 2017 to January 2020. A total of three hundred individuals were selected where 150 tobacco smoking anemic and 150 healthy volunteers were enrolled after taking informed consent from all the participants. The ethical clearance was obtained from Institutional Review Committee (KDC-IRC, Ref. No.- 08/07374). The inclusion criteria included equal number of age and gender matched anemic smokers ( 110 male and 40 female healthy non-smoking individuals). The reason behind a smaller number of female case was difficulty in availability of female individuals with smoking habit and the study was limited to our hospital. Patients with cancer, diabetes mellitus, liver dysfunction, other infections were excluded from the study.

A simple random sampling method was opted, and the sample size was 150 subjects, anemic smokers took 5-10 sticks per day, average age of study sample was $45.35 \pm$ 12.55 years with 110 males and females 40 . Almost all the patients were of underweight $(18.19 \pm 5.65) \mathrm{kg} / \mathrm{m}^{2}$. Similarly, 150 age and gender matched, 110 male and 40 female healthy non-smoking individuals were selected as the control. The healthy individuals were of normal BMI (body mass index), $20.45 \pm 4.59 \mathrm{~kg} / \mathrm{m}^{2}$.

Blood was collected in EDTA vials and centrifuged at 3000 rpm for 20 minutes for the separation of plasma and plain vials for serum extraction. Hemoglobin concentration less than $13.5 \mathrm{~g} / \mathrm{dl}$ for men, or $<12 \mathrm{~g} / \mathrm{dl}$ for women is the normal criteria for segregating anemia but smokers have elevated hemoglobin level. So various hematological parameters were assessed included; red blood cell count; 4.21 million/ $\mathrm{mm}^{3}$, mean corpuscular volume (MCV); $87.2 \mathrm{fL}$ mean corpuscular hemoglobin concentration; $34.26 \mathrm{~g} / \mathrm{dl}$, white blood cell; 6672 cells $/ \mathrm{mm}^{3}$ were the selection criteria for anemia.

Vitamin A was estimated by the method of Bessy et al, it was extracted into $n$-heptane layer and the absorbance was read at $327 \mathrm{~nm} .{ }^{9}$ Vitamin $\mathrm{C}$ was determined using dinitrophenyl hydrazine (DNPH) by Natelson method, the orange-red color complex formed was read at $520 \mathrm{~nm} .{ }^{10}$ Vitamin $\mathrm{E}$ was measured by Baker and Frank Method, red colored complex was measured at $520 \mathrm{~nm} .{ }^{11}$ The total antioxidant activity (TAA) was determined by Benzie and Strain method, blue colored complex was read at $593 \mathrm{~nm} .^{12}$ Lipid peroxidation product, thiobarbituric acid reactive substances (TBARS) was assessed by Satoh method, the pink colored complex was measured at $535 \mathrm{~nm} .{ }^{13}$ The lipid hydroperoxide (LPHO) was determined using Jiang method at $560 \mathrm{~nm} .{ }^{14}$ Nitrite and nitrate concentration were determined by Cortas and Wakid using activated cadmium. ${ }^{15}$ Superoxide dismutase (SOD) was determined by Kakkar method, the nicotinamide adenine dinucleotide-phenazine methosulfate-nitro blue tetrazolium formazan complex was measured at $560 \mathrm{~nm} .{ }^{16}$ Catalase (CAT) activity was estimated by Sinha method, ${ }^{17}$ glutathione peroxidase (GPx) was analyzed by Rotruck method. ${ }^{18}$ Glutathione was estimated by Beutler and Kelley method. ${ }^{19}$

All the data were processed and analyzed using SPSS 20.0 (Statistical Package for the Social Sciences). All the results are expressed as mean \pm standard deviation, the Independent sample t-test for was used for comparing this means values with statistical significance at $p<0.05$.

The controls selected were of healthy rather than nonsmoking anemic because when we did analysis, the difference was only in low hemoglobin level in anemic individuals. The anemic non-smoking subjects had lower antioxidants status as well as higher oxidants values which did not show any significance between my case and controls. The sample size was collected by following technique:

$$
\begin{aligned}
& n=\frac{Z^{2} \cdot p(1-p)}{d^{2}} \\
& \text { where, } Z=1.96 \\
& =\quad \begin{array}{l}
\text { value of the standard normal distribution } \\
\text { corresponding to a significance level of alpha }
\end{array} \\
& =\quad \begin{array}{l}
(1-\text { alpha }) / 2 \\
d
\end{array} \\
& \quad p=\text { absolute precision, } 5 \% \\
& n=1.96 \times 0.1 \times(1-0.1)=138.3
\end{aligned}
$$$$
(0.05)^{2}
$$

With $10 \%$ error, Sample size $=150$

\section{RESULTS}

A total of 300 subjects were selected for the study, among them 150 were anemic individuals with smoking habit and the rest 150 were the healthy age-gender matched healthy controls. The matched age of cases and controls was $45.35 \pm$ 12.55 years, and an equal number of male and female ratio could not be found because of the lack of anemic female 
smokers as compared to male. The number of sticks intake of males were more as compared to females in our study group. Hemoglobin level was found to be higher in anemic smokers. The association of raised hemoglobin in anemic smoking was found to be statistically significant as compared with their healthy counter parts. Likewise, the antioxidant defence system too, was found to diminished in the anemic smokers. Significant elevations were found in free radical analysing parameters such as thiobarbituric acid reactive substances, lipid hydroperoxide and nitric oxide and nitrite levels in anemic smokers which is shown (Table 1).

\section{DISCUSSION}

The prevalence of anemia ranges from $15-78 \%$ and the prevalence of smoking and tobacco use is $56.5 \%$ in men and $19.5 \%$ in women and is considered higher in comparison to other countries. ${ }^{3-7}$ Each year seven million people are dying of tobacco smoking worldwide with several associated complications, among them anemia is one. Smoking has more effect on the health because it is associated with higher number of cigarettes smoked. ${ }^{1-3}$ The present study indicates marked increase in reactive oxygen species production as reflected by elevated oxidant and decreased antioxidants parameters in anemic smokers. ${ }^{5-8} 20-50 y$ rs time is the critical time for the health and future development and cigarette smoking can influence lifelong health risk. ${ }^{20-24}$

Smoking is the powerful risk factor for anemia because it contains toxic vigorous molecules like aldehydes, heavy metals, hydrogen cyanide, low molecular weight phenols, nitrosamines, polycyclic aromatic hydrocarbons, metallic ions, hydroxyl radicals. ${ }^{23-26}$ The large volume of oxidants from the smoke phase as well as the tar phase of cigarette smoke produces copious amounts of ROS, which are responsible for increased lipid peroxidation and its harmful consequences. Oxidative stress occurs when there is imbalance between oxidant agents, insufficient antioxidant defence mechanism. Reactive oxygen species generated by cigarette smoke plays an important role in elevation of oxidative stress, and malondialdehyde, nitric oxide, lipid hydroperoxide end products is one of the indicators of oxidative stress. ${ }^{25-30}$

Our study corroborates with that of Ugbebor et al, who found significantly higher hemoglobin concentration in smokers. ${ }^{25}$ The high $\mathrm{Hb}$ concentration in smokers may be since smoking causes excessive production of carbon monoxide leading to formation of carboxy $\mathrm{Hb}$. As $\mathrm{Hb}$ has 200 times more affinity to carbon monoxide than oxygen, there is a stark unavailability of $\mathrm{Hb}$ for Oxygen carriage, shifting the $\mathrm{Hb}-\mathrm{O}_{2}$ dissociation curve to the left. ${ }^{25,26}$ As a compensatory mechanism, the body tries to produce more $\mathrm{Hb}$ by increasing the rate of erythropoiesis. ${ }^{1,3,4}$ This can attribute to the higher membrane peroxidation and altered RBC volume coupled with the cellular oxidative stress, makes RBC more fragile in smokers with anemia. ${ }^{28,31-34}$

Red blood cells are at increased risk from oxidative processes for a diverse reason. It is continually exposed to high oxygen tensions, and $\mathrm{Hb}$ is susceptible to auto oxidation. ${ }^{1-4,22-24}$ RBCs are unable to repair damaged components by resynthesis.
Therefore, RBC is completely dependent on the antioxidant enzymes catalase, superoxide dismutase, and glutathione peroxidase through out 120 days of its life span. These enzyme systems build up an efficient defence system and are particularly involved in the detoxification of the cell from oxygen-free radicals. ${ }^{31-33}$ Erythrocyte glutathione peroxidase (GPx) activity plays amore sensitive and better indicator of smoking induced oxidative stress in anemic individuals. GPx detoxifies the $\mathrm{H}_{2} \mathrm{O}_{2}$ produced by superoxide dismutase (SOD) action and converts lipid hydroper oxides to nontoxic alcohols. Hence, GPx is considered to act as a chain-breaking antioxidant. Our findings also supported the results who have studies the influence of gender, age and cigarette smoking on antioxidant enzymes and have reported significantly reduced GPx activity in smokers. Significant lower activity of GPX and SOD in the erythrocytes of smokers, while catalase (CAT) activity remains unchanged was reported by study of Orhan et al. ${ }^{26}$ Our study as well as few researchers have clearly exhibited that erythrocyte GPx and SOD activities serves as a potent marker of antioxidant defence in smoking and anemic subjects. ${ }^{28,29,34,35}$

During oxidative stress, the glutathione (sulfhydryl) groups protects other cellular structures against free radical induced oxidation and disulphide band formation. Free radicals present in cigarette increases peroxidation products in smokers' blood and vascular tissues are chiefly responsible for these deleterious effects. Increased exposure to cigarette smoke was shown to decrease plasma antioxidants in vitro and to lower vitamin Clevels in the plasma and leucocytes of smokers. Many studies have confirmed higher RBC lipid peroxidation in smokers as related to non-smokers. In addition, it has been confirmed that glutathione levels decrease in biological tissues due to exposure to cigarette smoke. ${ }^{35}$

Anemia and smoking have emerged as major public health problem worldwide. Remarkably, there appears a link between smoking and levels of haemoglobin. Smoking increases erythropoiesis by producing more carboxy haemoglobin and making $\mathrm{Hb}$ unavailable for oxygen transport, shifts the $\mathrm{Hb}$ dissociation curve in the left side, resulting in a reduction in ability of $\mathrm{Hb}$ to deliver oxygen to the tissue. For compensation of decreased oxygen delivering capacity, higher haemoglobin level is maintained by smokers. Smoking decreases the levels of vitamin C which, in turn, predisposes the individual to iron deficiency anemia due to decrease in the absorption of iron. Smoking is also known to cause macrocytosis mainly by altering the levels of vitamin $B_{12}$ and folic acid. Oxidative stress, inflammation, bone marrow depression, and gastritis caused by smoking also result in anemia, induces change in hematological parameters thus acts as a predisposing factor for multi system diseases. ${ }^{24-27,31-35}$

Tobacco smoking is the most important risk factor accompanying with chronic bronchitis, emphysema, oxidative stress, inflammation, bone marrow depression, gastritis, exacerbates respiratory disease in children (parental smoking), causes pediatric deaths from low birth weight, short gestation, respiratory distress syndrome and 
sudden infant death syndrome (maternal smoking). Numerous health problems; hematological and physiological changes occurs and attachment of peroxidants to RBC membranes increases RBChemolysis. ${ }^{24,27,36}$

Our results undoubtedly show an appreciable increase in the malondialdehyde (MDA) levels in the erythrocytes ofanemic smokers undertaken in this study in comparison to non-anemicsmokers. The high ranges of MDA, lipid hydroperoxides and nitric oxide levels in erythrocytes of anemic smokers reveals the consequence of uncontrolled lipid peroxidation and suppressed enzymatic and nonenzymatic antioxidant defence. ${ }^{36-39}$ The process of uncontrolled lipid peroxidation in biological system due to toxic chemicals and oxidants presented by cigarette smoke may be accompanied with loss of essential polyunsaturated fatty acids, formation of toxic hydroperoxides and other free radicals damaging macro-molecules like lipids, proteins, DNA, etc. Based on the findings of the present study, it may be concluded that smoking is associated with the generation of free radicals, abnormalities and peroxidation of vital body molecules which implies increased risk not only the anemic smokers but also their passive smokers who might be their family members, colleagues, etc. However, additional studies with further tissue damage parameters are needed to evaluate the oxidative stress in anemic smokers. Further, the study can be carried out increasing the sample size and multi-centric study can be done to highlight the effects of antioxidants and lipid peroxidation on anemic smokers is recommended.

REFERENCES

1. Asgary S, Naderi GH, Ghannady A. Effects of cigarette smoke, nicotine and cotinine on red blood cell hemolysis and their - $\mathrm{SH}$ capacity. Exp Clin Cardiol. 2005; 10(2): 116-119.PMID: 19641671

2. Waseem SMA, Alvi AB. Correlation between anemia and smoking: study of patients visiting different outpatient departments of integral institute of medical science and research, Luckhnow. National J Physiol, Pharmacy and Pharmacology. 2020; 10(2):149154.doi: 10.5455/njppp.2019.9.0412805122019

3. Sharma D, Amgain K, Panta PP, Pokhrel B. Hemoglobin levels and anemia evaluation among pregnant women I the remote and rural high lands of mid-western Nepal: a hospital-based study. BMC Pregnancy and Children. 2020; 20: 182.doi: 10.1186/s12884-020-02870-7

4. Christian P, West KP, Kimbrough-Pradhan E, Leclerq SC, Khatry SK, Shrestha SR. Cigarette smoking during pregnancy in rural Nepal. Risk factors and effects of beta carotene and vitamin A supplementation. European J Clin Nutrition. 2004; 58: 204211.doi: $10.1038 /$ sj.ejcn.1601767

5. Pham-Huy LA. He H, Pham-Huy C. Free radicals, antioxidants in disease and health. Int J Biomed Sci 2008;4(2): 89-96. PMID: 23675073

6. Shah BK, Nepal AK, Agarwal M, Singh AK. The effects of cigarette smoking on hemoglobin levels compared between smokers and nonsmokers. Sunsari Technical College Journal. 2012; 1(1): 4244.PMID: 2395196

7. Gautam S, Min H, Kim H, Jeong HS. Determining factors for the prevalence of anemia in women of reproductive age in Nepal: evidence from recent national survey data. PLOS. 2019; 14(6): e0218288.doi: 10.1371/journal.pone.0218288

8. Pizent A, Lazarus M, Kovacic J, Lovakovic BT, Karaconji IB, Semren TZ. Cigarette smoking during pregnancy: effects on antioxidant enzymes, metallothionein and trace elements in mother-newborn pairs. Biomolecules. 2020; 10: 892.https://doi.org/10.3390/ biom 10060892

\section{CONCLUSIONS}

Our study on smoking anemic individuals showed increased hemoglobin status as compared with their controls. Regardless of high concentration of hemoglobin, cases showed low status of non-enzymatic antioxidants and high levels of oxidants as compared to controls. The invasion of the RBC membrane by oxidants, cigarette smoking alters the cellular metabolic function and can ultimately lead to early erythrocyte hemolysis.

\section{LIMITATIONS OF STUDY}

Limitations of the present study included: smoker anemic patients was difficult to find, and so were less in number, study group and healthy participants were confined to our institution only as per NHRC rule. Anemic female with smoking cases were very few, so male to female ratio could not be maintained.

\section{ACKNOWLEDGEMENTS}

We would like to acknowledge Department of Biochemistry, Pathology, Kantipur Dental College Teaching Hospital \& Research Center, Basundhara, Kathmandu and all participants who permitted us to draw blood and supported this research work.

\section{CONFLICT OFINTEREST}

None

9. Bessey OA, Lowry OH, Brock MJ, Lopez JA. The determination of vitamin $A$ and carotene in small quantities of blood serum. J Biol Chem. 1946; 166: 177-188

10. Natelson S. Determination of ascorbic acid by 2, 4- dinitrophenyl hydrazine. In: Techniques of clinical chemistry. 3rdEd.USA: Charles C Thomas Springfield. 1971; 165-166

11. Baker H, Frank O. Determination of Vitamin E. Determination of vitamin E. In: Clinical vitaminology. USA. 1968; 172

12. Benzie IFF, Strain JJ. The ferric reducing ability of plasma (FRAP) as a measure ofantioxidant power: The FRAP assay. Analytical Biochemistry. 1996: 239; 70-76.doi: 10.1006/abio.1996.0292

13. Buege JA, Aust SD. Microsomal lipid peroxidation. Methods Enzymol. 1978; 52: 302-310.doi: 10.1016/s0076-6879(78)52032-6

14. Jiang ZY, Hunt JV, Wolff SP. Ferrous ion oxidation in the presence of xylenol orange for detection of lipid hydroperoxides in low density lipoprotein. Anal Biochem. 1992; 202: 384-389.doi: 10.1016/00032697(92)90122-n

15. Cortas NK, Wakid NW. Determination of inorganic nitrate in serum and urine by a kinetic cadmium-reduction method. ClinChem1990; 36: 1440-1443.PMID: 2387039

16. Kakkar P, Das B, Vishwanathan PN. A modified spectrophotometric assay of superoxide dismutase. Ind J BiochemBiophys 1984; 21 : 130-132.PMID: 6490072

17. Sinha KA. Colorimetric assay of catalase. J Biochem. 1972; 47: 389.DOI: 10.1016/0003-2697(72)90132-7

18. Rotruck JT, Pope L, Ganther HE, Swanson AB. Selenium biochemical role as a component of glutathione peroxidase. Science. 1973; 179: 588.DOI: 10.1126/science.179.4073.588

19. Beutler E, Duran O, Kelly BM. Improved methods for the determination of blood glutathione. J Lab Clin Med. 1963; 61: 882888.PMID: 13967893 
20. Makwana NR, Shah VR, Yadav S. A study on prevalence of smoking and tobacco chewing among adolescents in rural areas of Jamnagar district, Gujarat state. J Med Sci Res 2007;1(1):47-50.

21. Meera KS. Oxidative balance in smokers with and without hypertension. Biomed Res 2011;22(3):267-272

22. Metta S, Uppala S, Basalingapa DR, Badeti SR, Gunti SS. Impact of smoking on erythrocyte indices and oxidative stress in acute myocardial infarction. J Dr NTR University of Health Sciences. 2015; 4(3): 159-164.DOI: 10.4103/2277-8632.165400

23. Devasagayam TPA, Tilak JC, Boloor KK, Sane KS, Ghaskadbi SS, Lele RD. Free radicals and antioxidants in human health: current status and future prospects. JAPI. 2004; 52: 794-803.PMID: 15909857

24. Shinde A, Ganu J, Naik P. Effect of free radicals and antioxidants on oxidative stress: a review. J Dental \& Applied Sciences. 2012; 1(2): 63-66.DOI: 10.4103/2277-4696.159144

25. Ugbebor OU, Oseni BA, Arinolas OG, Osazuwa F, ZabayoOJ,Dirisu JO et al. Red blood cell susceptibility to oxidants in chronic cigarette smokers. Res J Pharm BiolChem Sci. 2011; 2: 380-388

26. Orhan $\mathrm{H}$, Evelo $\mathrm{CT}$, Sahin G. Erythrocyte antioxidant defence response against cigarette smoking in humans - the glutathione $\mathrm{S}$ transferase vulnerability. J BiochemMolToxicol. 2005; 19: 226233.DOI: $10.1002 /$ jbt.20088

27. Longman JM, Pritchard C, McNeill A, Csikar J, Croucher RE. Accessibility of chewing tobacco products in England. J Public Health. 2010; 32(3): 372-378doi: 10.1093/pubmed/fdq035

28. Yang WS, Leatherdale ST, Ahmed R. Smoking susceptibility among never-smokers: data from the 2006-07 national youth smoking survey. Can J Public Health. 2011; 102(4):254-257.doi: 10.1007/ BF03404043

29. Uprety S, Poudel IS, Ghimire A, Singh N, Poudel M, Rayamajhi RB, Pokhrel PK. Knowledge on health effects and practices of smoking among the smokers in eastern terai regions of Nepal. J Chitwan Med Coll. 2014; 4(7): 22-25.DOI: 10.3126/jcmc.v4i1.10843

30. Gautam N, Jayan A, Dubey RK, Jha SK, Dhakal PK, Baral N, Lamsal M. Comparative study of impact of smoking in healthy and pulmonary tuberculosis patients measured by indices of oxidative stress. International J Medical Sciences and Biotechnology. 2013; 1(4):45-54
31. Dass BP, Jaganmohan P, Sravanakumar P. Changes in hematological and biochemical parameters insmokeless tobacco chewers in coastal belt of Andhra Pradesh, India. European J Biological Sciences. 2013; 5(1): 29-33.DOI: 10.5829/idosi.ejbs.2013.5.1.728

32. Premananda R, Santhosh KPH, Mohan A. Study of thiobarbituric acid reactive substances and total reduced glutathione as indices of oxidative stress in chronic smokers with and without chronic obstructive pulmonary disease. The Indian $j$ Chest Diseases \& Allied Sciences. 2007; 49: 9-12.PMID: 17256560

33. Sreeramareddy CT, Kishore PV, Paudel J, Menezes RG. Prevalence and correlates of tobacco use amongst junior collegiates in twin cities of western Nepal. BMC Public Health. 2008; 8: 97. doi: 10.1186/1471-2458-8-97

34. Nsonwu-Anyanwu AC, Offor SJ, John II. Cigarette smoke and oxidative stress indices in male active smokers. Reactive Oxygen Species. 2018; 5(15).http://dx.doi.org/10.20455/ros.2018.829

35. Fearon IM, Philips G, Carr T, Taylor M, Breheny D, Faux SP. The role of oxidative stress in smoking related diseases. Mini-Reviews in Organic Chemistry. 2011; 8: 360-371.DOI: 10.2174/1570193117 97440317

36. Bentley ME, Griffiths PL. The burden of anemia among women in India. European J Clinical Nutrition. 2003; 57: 52-60.DOI: 10.1038/ sj. ejcn.1601504

37. Chandyo RK, Henjum S, Ulak M, Thorne-Lyman AL, Ulvik RJ, Shrestha PS, Locks L. The prevalence of anemia and iron deficiency is more common in breastfed infants than their mothers in Bhaktapur, Nepal. European J ClinNutr. 2016; 70: 450-462.DOI: 10.1038/ejcn.2015.199

38. Bhandary S, Shrestha A. Prevalence of anemia among nonpregnant and pregnant women of reproductive age in Nepal. JGPEMN. 2011; 21-26

39. ValavanidisA, VlachogianniT, Fiotakis K. Tobacco Smoke: Involvement of Reactive Oxygen Species and Stable Free Radicals in Mechanisms of Oxidative Damage, Carcinogenesis and Synergistic Effects with Other Respirable Particles. Int J Environ Res Public Health. 2009; 6(2): 445-462.doi: 10.3390/ijerph6020445 